\title{
Calcined eggshell (CES): An efficient natural catalyst for Knoevenagel condensation under aqueous condition
}

\author{
SURESH PATIL ${ }^{\mathrm{a}, *}$, SWATI D JADHAV ${ }^{\mathrm{a}}$ and M B DESHMUKH ${ }^{\mathrm{b}}$ \\ ${ }^{a}$ Organic Research Laboratory, Padmabhushan Dr. Vasantraodada Patil College, \\ Sangli 416 312, India \\ ${ }^{\mathrm{b}}$ Department of Chemistry, Shivaji University, Kolhapur 416 004, India \\ e-mail: sanyujapatil@yahoo.com
}

MS received 7 July 2012; revised 6 April 2013; accepted 17 May 2013

\begin{abstract}
A convenient, eco-friendly and economic method for Knoevenagel condensation of aromatic aldehydes with active methylene compounds using calcined eggshell (CES) as an efficient natural catalyst in aqueous medium has been reported. CES is a new, ecologically safe and inexpensive green catalyst obtained from renewable resources.
\end{abstract}

Keywords. Natural catalyst; CES; Knoevenagel condensation; green catalyst; renewable resources.

\section{Introduction}

Knoevenagel condensation of aldehydes with active methylene compounds is an important method used for the synthesis of different pharmaceutically important organic compounds. ${ }^{1}$ Formation of carbon-carbon bond in organic syntheses has attracted attention of many researchers. Knoevenagel condensation is one of the important reactions to achieve carbon-carbon bond formation in organic syntheses. Some eco-friendly methods for Knoevenagel condensation have been reported using green catalysts and under solvent-freeconditions. However, completion of reaction with high yield has been achieved by maintaining high reaction temperature and long reaction time. Some newly reported methods employ catalysts such as sulphated zirconia, ${ }^{2}$ diazabicyclo[5.4.0] undec-7-ene (DBU), ${ }^{3}$ silica supported ammonium acetate, ${ }^{4}$ guanidine, ${ }^{5}$ with different reaction conditions. The Knoevenagel condensation is carried out using catalysts such as polymeric sulphonate of piperazine, ${ }^{6}$ thiourea, ${ }^{7} \mathrm{MgO} / \mathrm{ZrO}_{2},{ }^{8}$ ionexchange resin, ${ }^{9}$ potassium sorbate, ${ }^{10}$ and also in the presence of various solvents. ${ }^{11}$

The Knoevenegel condensation is also performed using Lewis acids such as $\mathrm{LaCl}_{3} \cdot 7 \mathrm{H}_{2} \mathrm{O},{ }^{12} \mathrm{ZnCl}_{2},{ }^{13}$ $\mathrm{I}_{2} / \mathrm{K}_{2} \mathrm{CO}_{3},{ }^{14}$ and $\mathrm{CuCl}_{2} \cdot{ }^{15}$ At the same time some base catalysts such as alumina, ${ }^{16}$ ethylene diamine, ${ }^{17}$ dimethyl amino pyridine, ${ }^{18}$ alkaline earth oxides, ${ }^{19}$ have been reported which work efficiently for Knoevenagel condensation. Recently, alumina-supported

*For correspondence
$\mathrm{MOF}^{20}$ eggshell as porous superhydrophobic material is reported for Knoevengel condensation. However, many reported methods have various drawbacks such as prolonged reaction time, toxicity and use of harmful organic solvents. Introduction of clean procedures utilizing eco-friendly green catalysts have attracted great attention of workers.

Recently, we have developed calcined eggshell (CES) as a natural catalyst and we found that it works efficiently for Knoevenagel condensation between aromatic and hetero aromatic aldehydes and active methylene compounds.

CES has been developed from processing of waste eggshells. Eggshell material mainly consists of high percentage of calcium carbonate, nearly about $94 \%$. $^{21}$ Waste eggshells have been utilized as humidity adsorbent, ${ }^{22}$ as an adsorbent in the removal of chromium from its aqueous solution, ${ }^{23}$ and also as a low cost solid catalyst for biodiesel production, ${ }^{24}$ as a catalyst for lactose isomerization to lactulose. ${ }^{25}$ Being a natural source of calcium, eggshell powder can serve as a good calcium supplement in prevention and treatment of osteoporosis. ${ }^{26}$

\section{Experimental}

\subsection{Materials and methods}

All the chemicals used were of commercial reagent grade. The carbonyl compounds and active methylene compounds were purified by standard procedures and 


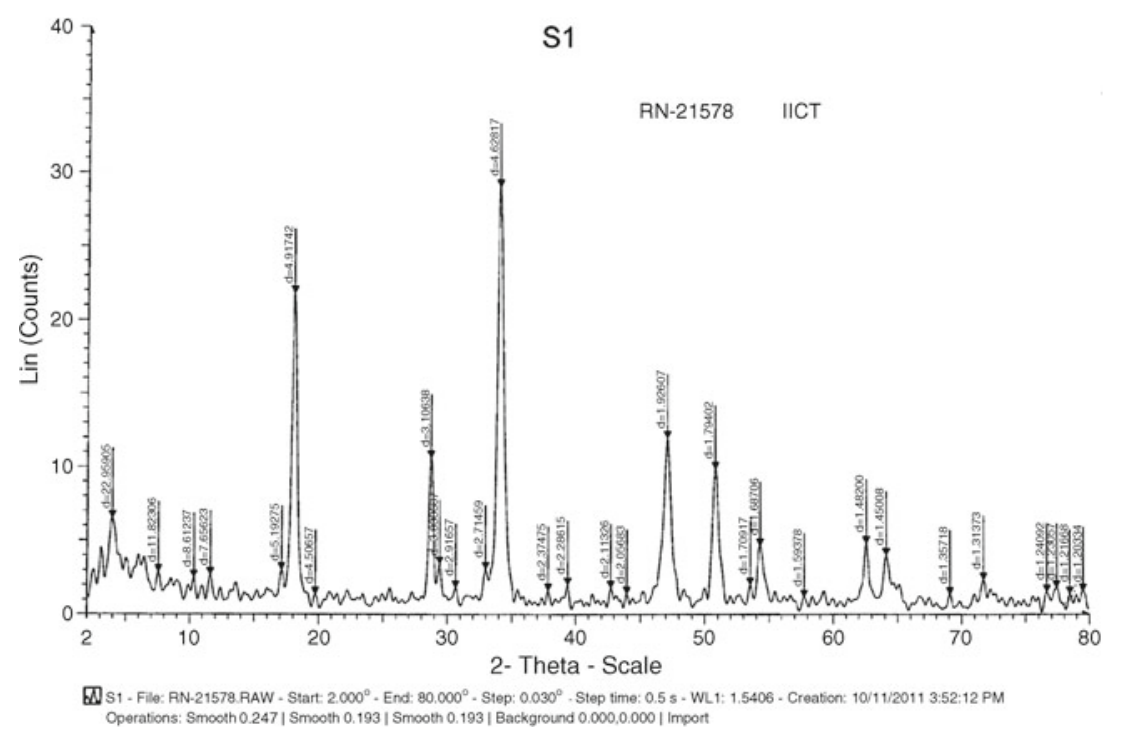

Figure 1. X-ray diffraction pattern of CES.

purity was determined by thin-layer chromatography (TLC). The ${ }^{1} \mathrm{H}$ NMR spectra were measured with Avance-300 NMR spectrophotometer. IR spectra were obtained using potassium bromide pallets on Bruker ALPHA FT-IR Spectrometer. Melting points were measured on open capillary method on DBK-programmable melting point apparatus. Purity of the substrates and completion of reactions were checked by TLC using Merck silicagel $60 \mathrm{~F}_{254}$ plates.

2.1a Preparation of catalyst CES: The waste eggshells were collected, cleaned and dried in an oven at $100^{\circ} \mathrm{C}$. After crushing, the raw eggshell powder was calcined at heating rate $2^{\circ} \mathrm{C} / \mathrm{min}$ in Muffle furnace up to $900^{\circ} \mathrm{C}$ and this temperature was maintained for $3 \mathrm{~h}$. After thermal treatment, most of the organic materials were burnt out and the eggshell got transformed

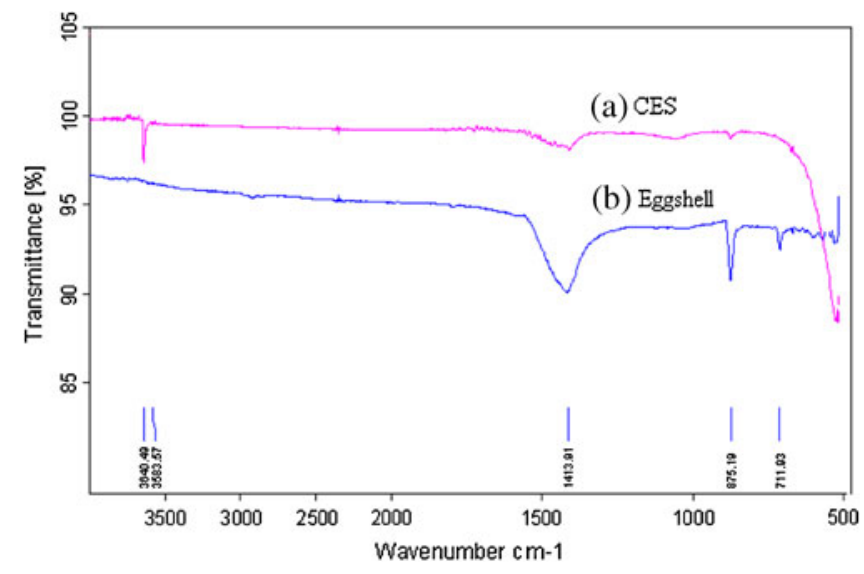

Figure 2. IR spectra of (a) CES and (b) Eggshell powder. into white soft powder, which was denominated as CES.

2.1b Characterization of catalyst: Aqueous 1\% CES solution was checked on $\mathrm{pH}$ meter and it was found that aqueous CES is strongly alkaline with $\mathrm{pH}$ 13.9.

Formation of suitable active phase of CES was found by X-ray diffraction (XRD) and confirmed by FT-IR spectra. The X-ray powder diffraction analysis (XRD) of CES sample (figure 1) shows characteristic peaks of $\mathrm{CaO}$ at $2 \theta=32.97,37.85,53.57$, peaks of $\mathrm{Ca}(\mathrm{OH})_{2}$ at $2 \theta=17.06,28.71,34.08,47.14,50.8$ and at $2 \theta=$ 29.37, 39.38 characteristics peaks of $\mathrm{CaCO}_{3}$.

The IR spectra of CES (figure 2a) shows a sharp band at $3640.49 \mathrm{~cm}^{-1}$ due to active phase $\mathrm{Ca}(\mathrm{OH})_{2}$, which supports for adsorption of water on $\mathrm{CaO}$ and disappearance of broad band at $1413.91 \mathrm{~cm}^{-1}$, sharp

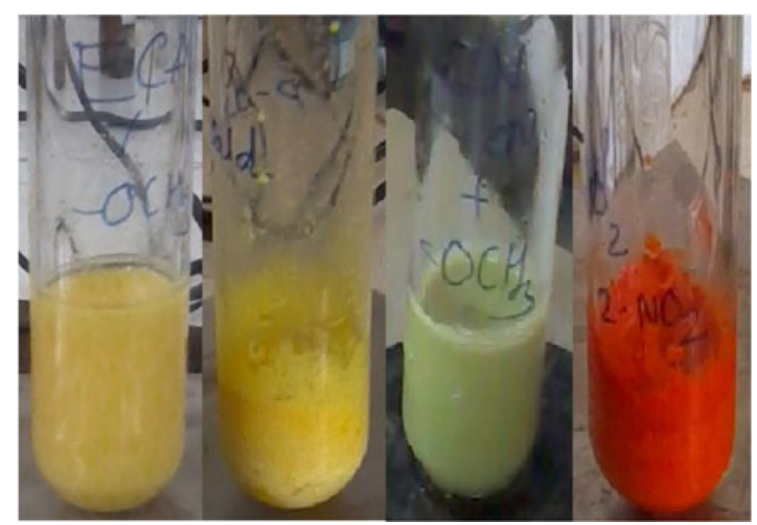

Figure 3. Product formation during reactions for entries 2, 3, 11, 14 (table 1). 


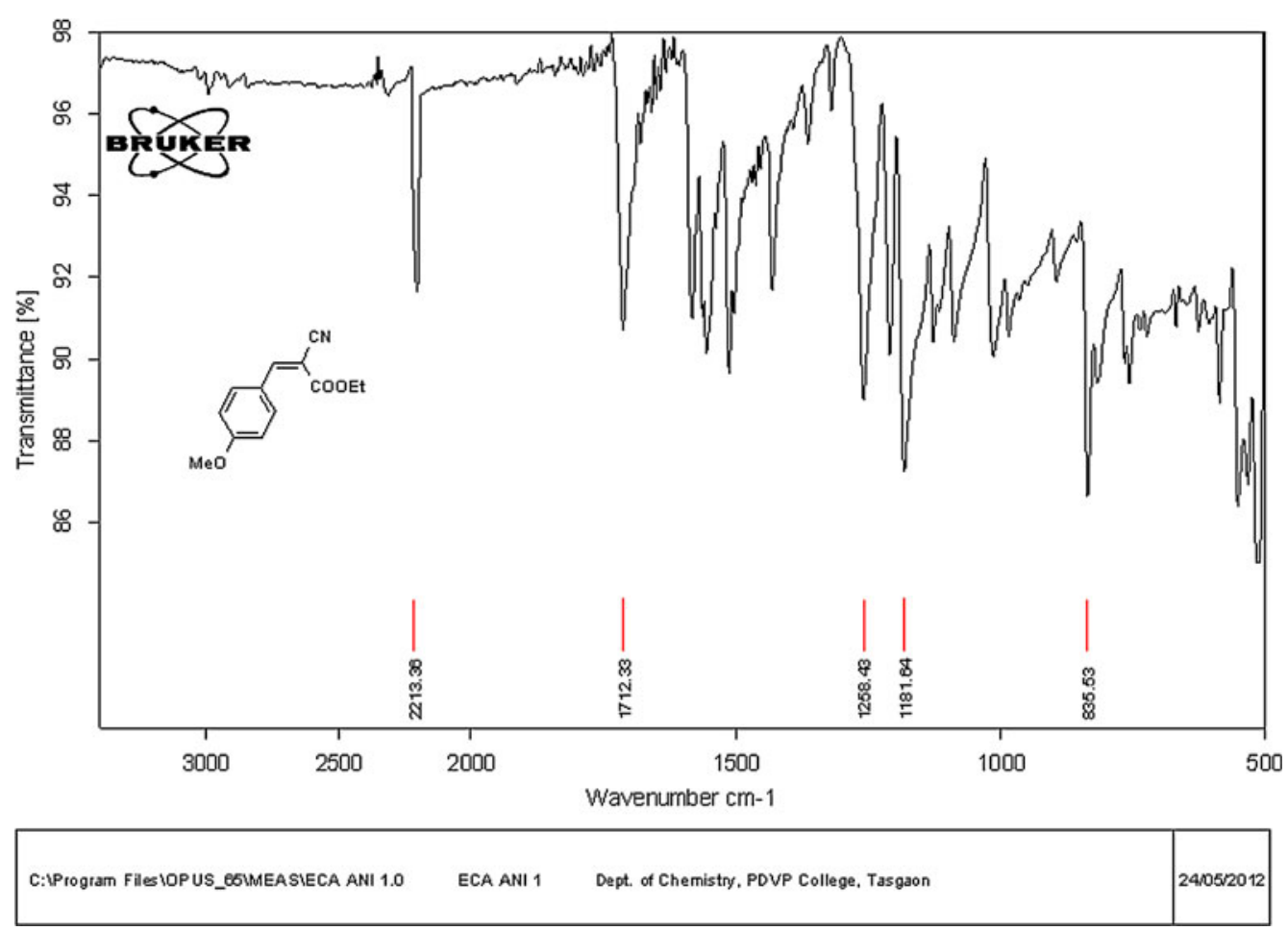

Figure 4. IR spectra of ethyl-2-cyano-3-(4-methoxyphenyl) prop-2-enoate (table 1, entry 2).

bands at $875.19,711.93 \mathrm{~cm}^{-1}$ which are characteristics of $\mathrm{CaCO}_{3}$ observed in IR spectra of eggshell powder (figure 2b).

2.1c General method for synthesis of $(2-$
Nitrobenzylidene)propanedinitrile $(\mathbf{1 4}):$ To the mixture of 2-nitrobenzaldehyde $(1.51 \mathrm{~g}, 10 \mathrm{mmol})$ and malononitrile $(0.66 \mathrm{~g}, 10 \mathrm{mmol})$ in $2 \mathrm{~mL}$ water, $2.5 \mathrm{wt} \%$ of CES catalyst (catalyst to solvent weight ratio) was added with constant stirring at room temperature. Progress of the reaction was monitored by TLC. After completion of the reaction (checked by 2 TLC), $5 \mathrm{ml}$ water was added and the reaction mixture was extracted with ethyl acetate. The organic phase was dried over $\mathrm{Na}_{2} \mathrm{SO}_{4}$ and ethyl acetate was removed

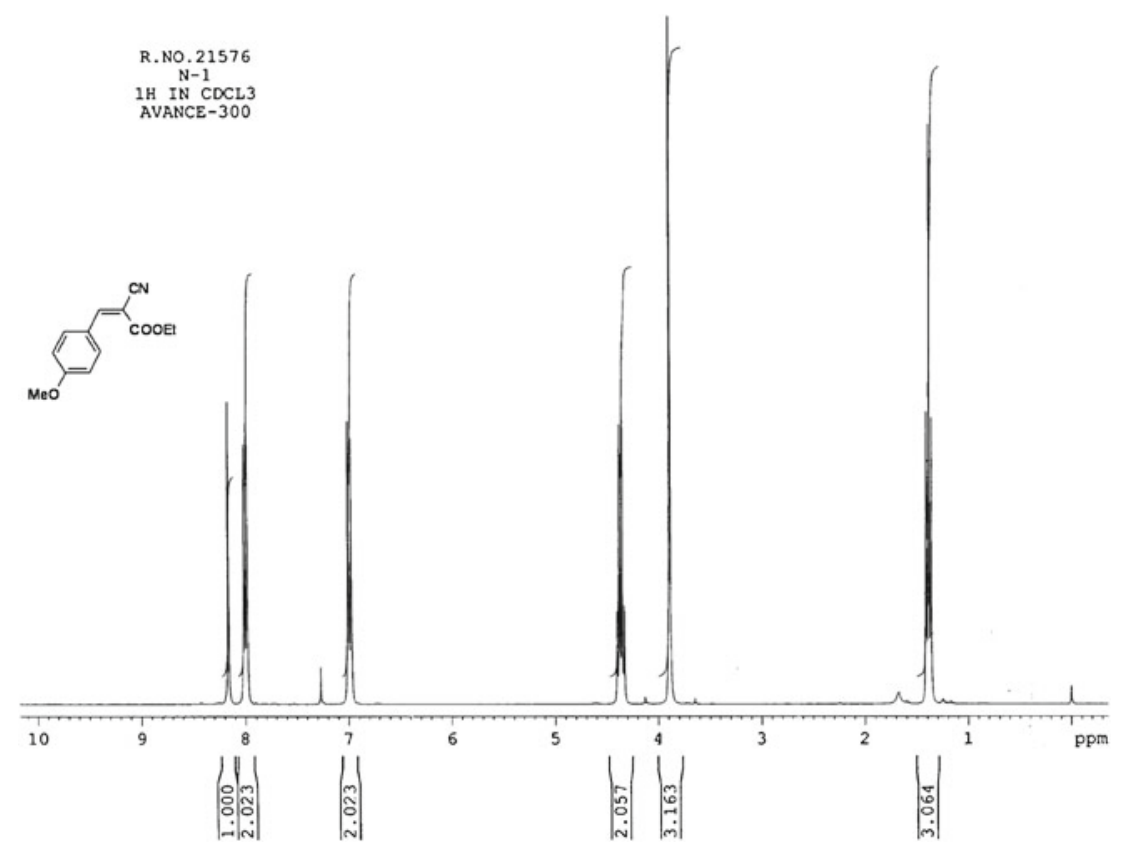

Figure 5. NMR spectra of ethyl-2-cyano-3-(4-methoxyphenyl)prop-2-enoate (table 1, entry 2). 


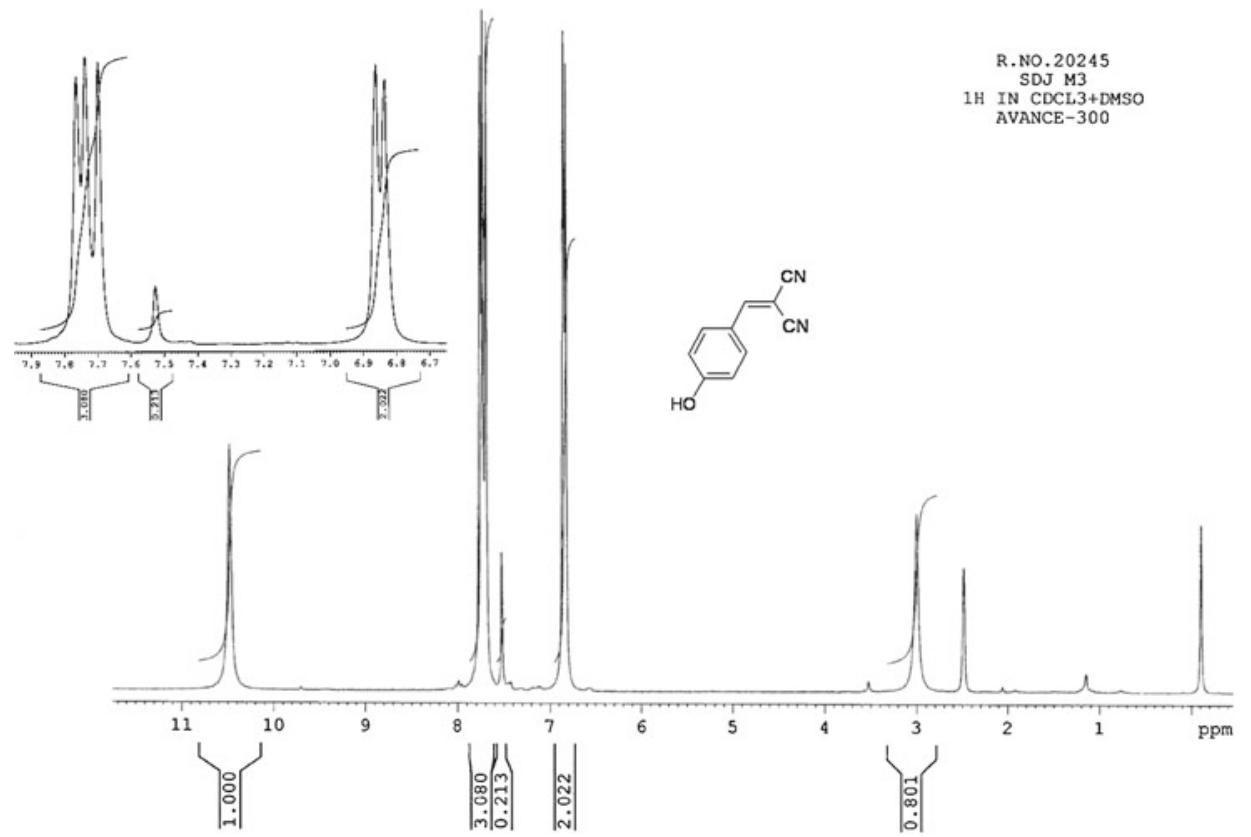

Figure 6. NMR spectra of (4-hydroxybenzylidene)propanedinitrile (table 1, entry 15).

under reduced pressure to get crude product. Recrystallization of crude product with ethanol produces orange crystalline product. All Knoevenagel products (1-19) were synthesized by following the same procedure and the products formed (figure 3) were confirmed by IR and NMR spectral analysis (figures 4-6).

\section{Result and discussion}

Knoevenagel condensation is basically reported as base catalysed reaction. In literature we found both acid as well as base catalysts reported efficiently for this condensation. As a part of our research work, we have reported the Knoevenagel condensation using lemon juice as a natural acid catalyst. ${ }^{27}$

In continuation with our research program concerning the development of natural catalysts, we are reporting here CES as an efficient natural base catalyst for Knoevenagel condensation of aromatic aldehydes and active methylene compounds (scheme 1).

To optimize the reaction conditions, initially we have decided to estimate the effect of solvent on the

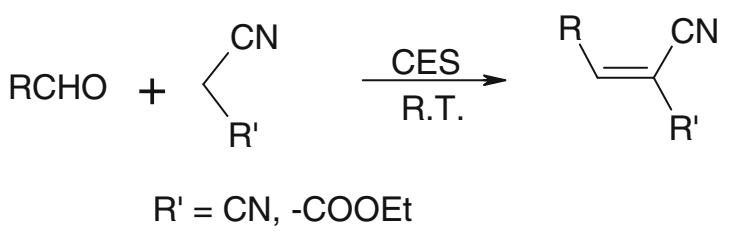

Scheme 1. CES catalysed Knoevenagel condensation.
CES catalysed Knoevenagel condensation in different organic solvents as well as in aqueous medium. For this study, the reaction between 4-nitrobenzaldehyde and malononitrile was chosen as model reaction. When the reaction was examined in different solvents such as water, ethanol, acetone, tetrahydrofuran (THF), toluene, acetonitrile, dichloromethane and chloroform, we found that the reaction proceeds smoothly at room temperature in water (table 1, entry 1) with $97 \%$ yield of product in $15 \mathrm{~min}$. While, in the presence of organic solvents, reaction proceeds comparatively with low yield (table 1, entries 2 to 8 ) taking more time. Hence, water can be used as best solvent due to high yield and shorter reaction time. Moreover, using water as the

Table 1. Optimization of reaction conditions using various solvents. ${ }^{a}$

\begin{tabular}{llcc}
\hline Sr. No. & \multicolumn{1}{c}{ Solvent } & Time $^{\mathrm{b}}(\mathrm{min})$ & Yield \\
\hline 1 & Water & 05 & 97 \\
2 & Ethanol & 30 & 87 \\
3 & Acetone & 35 & 84 \\
4 & Toluene & 60 & 90 \\
5 & THF & 120 & 82 \\
6 & Acetonitrile & 75 & 85 \\
7 & Dichloromethane & 110 & 84 \\
8 & Chloroform & 150 & 82 \\
\hline
\end{tabular}

${ }^{a}$ The reactions were carried out at ambient temperature using 4-nitro benzaldehyde $(10 \mathrm{mmol})$ and malanonitrile (10 mmol), $2.5 \mathrm{wt} \%$ CES in corresponding solvent.

${ }^{\mathrm{b}}$ Time reported in min monitored by TLC. 
Table 2. Knoevenagel condensation of aromatic aldehydes with active methylene compounds. ${ }^{\mathrm{a}}$

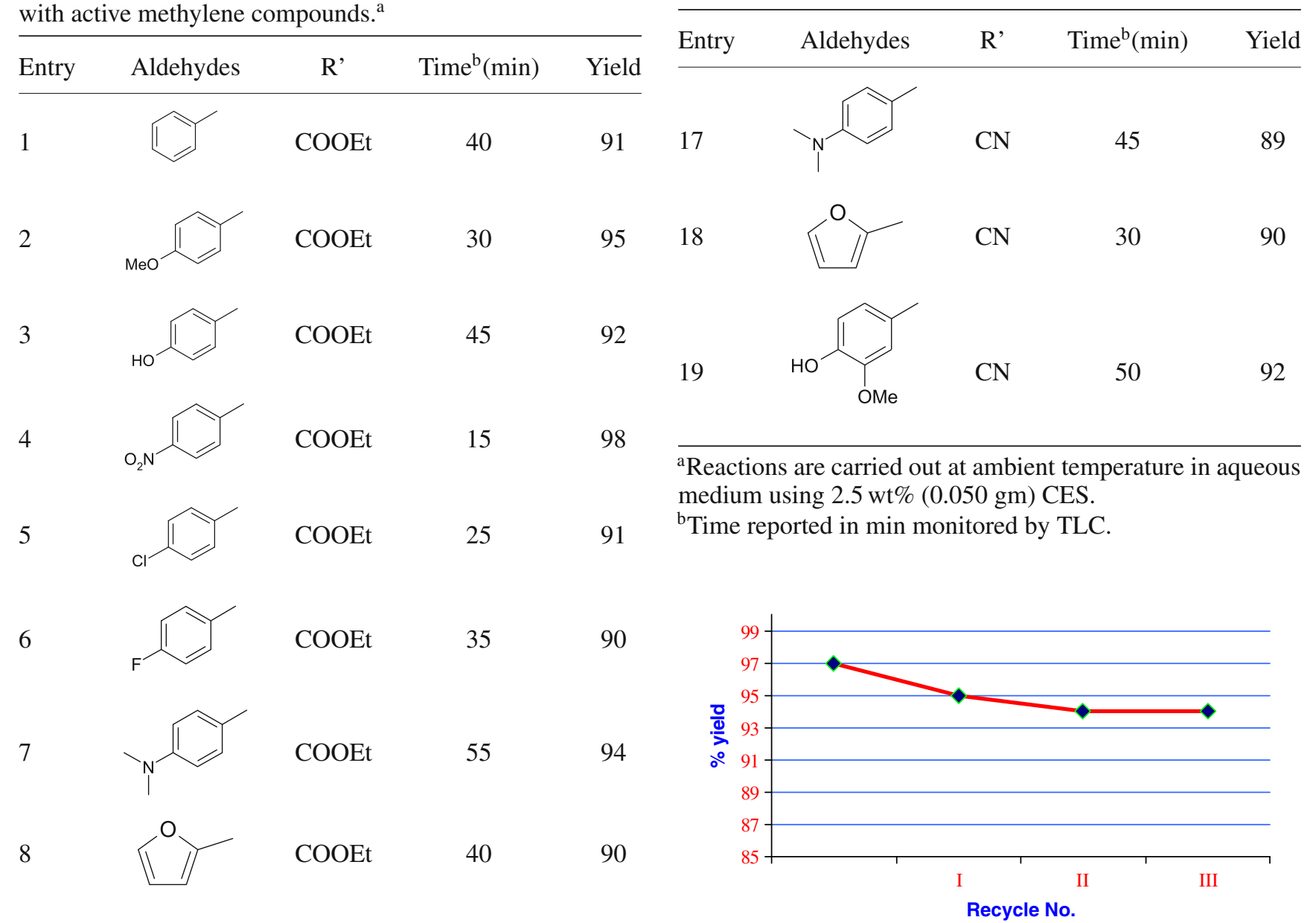

9<smiles>COc1cc(C)ccc1O</smiles>

COOEt $\quad 65$

10<smiles>Cc1ccccc1</smiles>

$\mathrm{CN}$

15

11<smiles>COc1ccc(C)cc1</smiles>

$\mathrm{CN}$<smiles>Cc1ccc(Cl)cc1</smiles>

$\mathrm{CN}$

05<smiles>Cc1ccc([N+](=O)[O-])cc1</smiles>

CN

05<smiles>Cc1ccccc1[N+](=O)[O-]</smiles>

CN

10

92<smiles>Cc1ccc(O)cc1</smiles>

$\mathrm{CN}$

10<smiles>Cc1ccc(F)cc1</smiles>

$\mathrm{CN}$
Table 2. (continued).

${ }^{a}$ Reactions are carried out at ambient temperature in aqueous medium using $2.5 \mathrm{wt} \%$ (0.050 gm) CES

Recycle No.

Figure 7. Efficiency of CES after recycling.

reaction medium made the separation process much easier than using other solvents. For example, with water as a solvent, the product could be obtained with high purity through simple filtration and washing with a little amount of water.

These observations indicate that, water increases the catalytic activity of CES effectively as compared to other organic solvents.

After optimization we subsequently examined the extent and feasibility of CES catalysed Knoevenagel condensation between different aromatic aldehydes and active methylene compounds, malononitrile and ethylcyanoacetate using $2.5 \mathrm{wt} \%$ of CES in aqueous medium. The results for all synthesized compounds are reported in table 2 .

A very small quantity of catalyst is sufficient for completion of reaction and for getting better yields. After completion of reaction the catalyst can be recollected easily from the reaction mixture.

CES catalyst gave good results when it was recycled. The reaction between 4-nitrobenzaldehyde (10 mmol) 
Table 3. Comparison of different catalysts used for synthesis of compound (10) Benzylidenepropanedinitrile $\left(\mathrm{R}=\mathrm{C}_{6} \mathrm{H}_{5}\right)$.

\begin{tabular}{|c|c|c|c|c|c|}
\hline Sr. No. & Catalyst & Solvent & Time & Condition & Yield (\%) \\
\hline 1 & $\mathrm{SO}_{4}^{-2} \& \mathrm{ZrO}_{2}^{2}$ & - & $180 \mathrm{~min}$ & Stirred in $\mathrm{N}_{2}$ atm. \& reflux & 89 \\
\hline 2 & Guanidine $^{5}$ & DCM & $4 \mathrm{~h}$ & RT & 89.8 \\
\hline 3 & Thiourea $^{7}$ & - & $2 \mathrm{~min}$ & MW & 82 \\
\hline 4 & Ionic liquid supportedproline ${ }^{28}$ & acetonitrile & $24 \mathrm{~h}$ & Stirred $80^{\circ} \mathrm{C}$ & 98 \\
\hline 5 & $\mathrm{SiO}_{2}-\mathrm{NH}_{4} \mathrm{OAc}^{29}$ & DCM & $7 \mathrm{~h}$ & Refluxed $60^{\circ} \mathrm{C}$ & 87 \\
\hline 6 & USY Zeolite ${ }^{30}$ & Benzene & $12 \mathrm{~h}$ & Reflux & 92 \\
\hline 7 & $\mathrm{AlPO}_{4}-\mathrm{Al}_{2} \mathrm{O}_{3}{ }^{31}$ & - & $1 / 4 \mathrm{~h}$ & Stirred at RT & 80 \\
\hline 8 & CTMAB $^{32}$ & Water & $1.5 \mathrm{~h}$ & Stirred at RT & 90.6 \\
\hline 9 & TEBA $^{33}$ & - & $10 \mathrm{~min}$ & Grinding at RT & 90 \\
\hline 10 & $\mathrm{NH}_{4} \mathrm{OAc}-\mathrm{Basic} \mathrm{Al}_{2} \mathrm{O}_{3}{ }^{34}$ & - & $6 \min$ & $\mathrm{MW}(850 \mathrm{~W})$ & 80 \\
\hline 11 & $\mathrm{MgBr}_{2} \cdot \mathrm{OEt}_{2}{ }^{35}$ & TEA, THF & $1-2 \mathrm{~h}$ & Stirred at RT & 98 \\
\hline 12 & $\mathrm{~K}_{2} \mathrm{CO}_{3}$ PEG $400^{36}$ & - & $60 \mathrm{~min}$ & Stirred at $90^{\circ} \mathrm{C}$ & 89 \\
\hline 13 & - & $\mathrm{H}_{2} \mathrm{O}$ & $2 \min$ & MW Irradiation ${ }^{37}$ & 89 \\
\hline 14 & CES & Water & $15 \mathrm{~min}$ & Stirred at RT & 92 \\
\hline 15 & $\mathrm{CaO}$ (without calcination) & Water & $15 \min$ & Stirred at RT & 91 \\
\hline 16 & $\mathrm{CaO}$ (calcined $900^{\circ} \mathrm{C}$ for $2 \mathrm{~h}$ ) & Water & $15 \min$ & Stirred at RT & 91 \\
\hline
\end{tabular}

and malononitrile $(10 \mathrm{mmol})$ was chosen for this purpose as model reaction to study the effectiveness of catalyst on recycling. The model reaction was carried out in the presence of $2.5 \mathrm{wt} \%$ of CES in water medium. The reaction mixture was stirred for appropriate time. After extraction of the product with ethylacetate, the aqueous phase containing CES was collected separately. The recovered aqueous solution containing CES was used as the reaction medium for the next cycle. The recycling was repeated for three times using similar amount of 4-nitrobenzaldehyde and malononitrile (figure 7). The catalyst was found to be efficient even after recycling.

Comparison of the results using CES catalyst with some other reported catalysts for Knoevenagel condensation (table 3) shows the efficiency of this catalyst. It furnishes high reaction yield, takes shorter reaction time, and small quantity of this inexpensive and readily available catalyst is sufficient to get good yield of expected products.

In order to compare the activity of CES with pure $\mathrm{CaO}$, the catalytic activity of $\mathrm{CaO}$ was also investigated for the model reaction. The results indicate that, CES and $\mathrm{CaO}$ (table 3, entries 14 to 16 ) have comparable catalytic performance. Since both have similar catalytic performance, we recommend here CES as best catalyst as it is derived from renewable resources, waste eggshell.

This natural CES catalyst helps to prevent use of hazardous chemicals as catalyst for this reaction. Use of easily available waste eggshells from renewable source as precursor of CES reduces cost of the process. The reaction is conducted using water as green solvent, which highlights the method as green method for Knoevenagel condensation.

\section{Conclusion}

The highly efficient green method is reported for the Knoevenagel condensation using CES as a natural catalyst resulting in good yields. Use of CES obtained from renewable natural source, mild reaction conditions, simple workup without involvement of any hazardous material quantify this method as an environmentally benign approach for Knoevenagel condensation. This work adds new catalyst in organic transformations and CES has been proved to be a potential alternative to soluble bases.

\section{References}

1. Jones G 1967 Organic reactions (New York: Wiley) vol. 15 , p. 204

2. Reddy B M, Patil M K, Rao K N and Reddy G K 2006 J. Mol. Catal. A: Chem. 258302

3. Ware M, Madje B, Pokalwar R, Kakade G and Shingare M 2007 Bull. Catal. Soc. India 6104

4. Gupta R, Gupta M, Paul S and Gupta R 2009 Bull. Korean Chem. Soc. 30(10) 2419

5. Han J, Xu Y, Su Y, She X and Pan X 2008 Catal. Commun. 92077

6. Wen X 2006 Indian J. Chem. Sect. B 45b 762

7. Li J P, Qiu J K, Li H J and Zhang G S 2011 J. Chin. Chem. Soc. $\mathbf{5 8} 268$

8. Gawande M B and Jayaram R V 2006 Catal. Commun. 7(12) 931 
9. Hein R W, Astle M J and Shelton J R 1961 J. Org. Chem. 26(12) 4874

10. Liu Q, Ai H and Li Z 2011 Ultrason. Sonochem. 18(2) 477

11. Hangarge R V, Sonwane S A, Jarikote D V and Shingare M S 2001 Green Chem. 3310

12. Narsaiaha A V and Nagaiah K 2003 Synth. Commun. 33 3825

13. Rao P S and Ratnam R V 1991 Tetrahedron Lett. 32 5821

14. Ren Y M and Cai C 2007 Synth. Commun. 372209

15. Attanasi O, Fillippone P and Mei A 1983 Synth. Commun. 131203

16. Kwon P S, Kim Y M, Kang C J, Kwon T W, Chung S K and Chang Y T 1997 Synth. Commun. 274091

17. (a) Cardillo G, Fabbroni S, Gentilucci L, Gianotti M and Tolomelli A 2003 Synth. Commun. 33 1587; (b) Acker D S and Hertler W R 1962 J. Am. Chem. Soc. 84 3370

18. Narsaiah A V, Basak A K, Visali B and Nagaiah K 2004 Synth. Commun. 342893

19. Moison H, Texier-Boullet F and Foucaud A 1987 Tetrahedron $\mathbf{4 3} 537$

20. Aguado S, Canivet J, Schuurman Y and Farrusseng D 2011 J. Catal. 284207

21. Tsai W T, Yang J M, Lai C W, Cheng Y H, Lin C C and Yeh C W 2006 Bioresour. Technol. 97488

22. Pongtonglor $\mathrm{P}$, Hoonnivathana E, Limsuwan $\mathrm{P}$, Limsuwan S and Naemchanthara K 2011 J. Appl. Sci. 11(21) 3659
23. Rajendran A and Mansiya C 2011 Br. J. Environ. Climate Change 1(2) 44

24. Wei Z, Xu C and Li B 2009 Bioresour. Technol. 100(11) 2883

25. Montilla A, Castillo M D D, Sanz M L and Olano A 2005 Food Chem. 90(4) 883

26. Rovensky J, Stancíkova M, Masaryk P, Svík K and Istok R 2003 Int. J. Clin. Pharmacol. Res. 23(2-3) 83

27. Deshmukh M B, Patil S S, Jadhav S D and Pawar P B 2012 Synth. Commun. 421177

28. Zhuo C, Xian D, Wei W J and Hui X 2011 International Scholarly Research Network ISRN Organic Chemistry, Vol. Article Id 676789, 5 Pages

29. Gupta R, Gupta M, Paul S and Gupta R 2009 Bull. Korean Chem. Soc. 30(10) 2419

30. Wang Q L, Ma Y D and Zuo B J 1997 Synth. Commun. 274107

31. Cabello J A, Campelo J M, Garcia A, Luna D and Marians J M 1984 J. Org. Chem. 495195

32. Wang S, Ren Z, Cao W and Tong W 2001 Synth. Commun. 31(5) 673

33. Rong L, Li X, Wang H, Shi D, Tu S and Zhuang Q 2006 Synth. Commun. 362407

34. Balalaie S and Nemati N 2000 Synth. Commun. 30869

35. Abaee M S, Mojtahedi M M, Zahedi M M and Khanalizadeh G 2006 Arkivoc 1548

36. Cao Y Q, Dai Z, Zhang R and Chen B H 2004 Synth. Commun. 34(16) 2965

37. El-Rahman N M A, El-Kateb A A and Mady M F 2007 Synth. Commun. 373961 